\title{
Alterações químicas em grãos de soja com a germinação
}

\author{
Chemical change in soybean grains with germination
}

\author{
Ana Paula Corazza MARTINEZ1, Patrícia Cristina Corazza MARTINEZ1, \\ Miriam Coelho SOUZA², Solange Guidolin CANNIATTI BRAZACA ${ }^{3 *}$
}

\begin{abstract}
Resumo
A soja apresenta importância comercial e nutricional, embora apresente fatores que possam diminuir o aproveitamento de nutrientes. A germinação tem efeito positivo na melhora nutricional do grão, pois ocorrem mudanças, as quais variam dependendo do tipo do vegetal, da variedade da semente e das condições da germinação. O trabalho teve por objetivo analisar grãos de soja antes e após germinação de 48 horas. Para isso foram quantificados: composição centesimal, inibidores de tripsina, ácido fítico, taninos, fenólicos totais, teor de ferro, disponibilidade de ferro in vitro, digestibilidade da proteína e atividade antioxidante (pelos métodos DPPH e ABTS). A germinação apresentou efeito na composição química e disponibilidade de proteínas e de ferro. Em relação aos teores de taninos, carboidratos disponíveis e atividade antioxidante pelos métodos DPPH e ABTS, houve redução significativa. O processo de germinação promoveu aumento do teor de umidade, lipídio, proteína, fibra solúvel, digestibilidade in vitro de proteína e fenólicos totais. Não apresentou diferença estatística para os teores de cinzas, fibra insolúvel, disponibilidade e teor de ferro, ácido fítico e atividade inibitória de tripsina. Apesar do período curto de germinação utilizado (48 horas) ocorreram mudanças em sua composição que foram satisfatórias, proporcionando aumento da qualidade nutricional. Palavras-chave: Glycine max (L.); antinutricionais; disponibilidade de ferro; antioxidante; proteína.
\end{abstract}

\begin{abstract}
Soybeans present commercial and nutritional importance, but they contain some components that decrease the availability of some nutrients. Germination has a positive effect on the increase of the nutritional quality of the grain due to the changes that occur in the process because of the difference in vegetable kind, variety of seed, and the germination conditions. The objective of this research was to analyze soybean grains before and after 48 hours germination. Centesimal composition, tripsin inhibitor, phytic acid, tannins, total phenolics, availability and amount of in vitro iron, in vitro protein digestibility and antioxidant activity analysis by DPPH and ABTS were performed. The germination process altered the chemical composition of the grain and the iron and protein availability. The results showed that germination reduced tannins, available carbohydrates, and the antioxidant activities by DPPH and ABTS methods. The germination process increased the moisture, lipid, protein, soluble fiber, in vitro protein digestibility, and total phenolics of the grain. Germination did not alter significantly the content of ash, insoluble fiber, amount of iron and its availability, phytic acid, and tripsin inhibitor. Although germination time was low, changes occurred in the grain composition promoting increase in the nutritional quality.

Keywords: Glycine $\max ($ L.); antinutrients; availability iron; antioxidant; protein.
\end{abstract}

\section{Introdução}

A soja (Glycine max Merril) é a mais importante oleaginosa e se destaca por fornecer diferentes produtos para a alimentação humana e animal e, possuir valor econômico no mercado nacional e internacional (SILVA et al., 2006). Possui compostos antinutricionais que apresentam efeitos adversos à nutrição humana e animal; baixa biodisponibilidade de minerais e baixa digestibilidade de proteínas (GHAVIDEL; PRAKASH, 2007; TRUGO et al., 2000).

Em 2004, a produção nacional de soja totalizou 50 milhões de toneladas ou $25 \%$ da safra mundial, estimada em 200 milhões de toneladas. Esse montante foi menor que a produção de 2003, quando o Brasil produziu 52 milhões de toneladas e participou com quase $27 \%$ da safra mundial (EMBRAPA, 2004). O Instituto Brasileiro de Geografia e Estatística (IBGE) aponta crescimento de $15,5 \%$ na safra de grãos de 2007 , sendo que a soja terá aumento de 5,5\% em relação à safra de 2006 que foi de 52.356.720 toneladas (INSTITUTO..., 2006).

Seus potenciais benéficos para a saúde vêm sendo muito investigados, quer seja pelo seu elevado teor de proteína de qualidade nutricional adequada, quer por seu conteúdo significativo em minerais e fibras, ou ainda devido a seu teor de compostos fenólicos ou polifenóis, que são metabólicos secundários das plantas, com diferentes estruturas químicas, apresentando extensa ação antioxidante e consequentemente efeitos benéficos à saúde (SILVA et al., 2006; FELIX; CANNNIATTI-BRAZACA, 2008; MELO; MARCOS FILHO; GUERRA, 2005).

Recebido para publicação em 26/7/2008

Aceito para publicação em 25/9/2009 (003711)

${ }^{1}$ Departamento de Agroindústria, Alimentos e Nutrição da Escola Superior de Agricultura "Luiz de Queiroz" - ESALQ, Universidade de São Paulo - USP

${ }^{2}$ Curso de Nutrição, Universidade Metodista de Piracicaba, Faculdade de Ciências da Saúde, E-mail: micsouza@unimep.br

${ }^{3}$ Departamento de Agroindústria, Alimentos e Nutrição, Escola Superior de Agricultura "Luiz de Queiroz" - ESALQ, Universidade de São Paulo - USP,

E-mail: sgcbraza@esalq.usp.br

${ }^{*}$ A quem a correspondência deve ser enviada 
Os polifenóis possuem poder antioxidante com característica anticarcinogênica, antiaterogênicas, antitrombóticas, antimicrobianas, vasodilatadora e analgésica, cuja ação é neutralizar os radicais livres além de outros efeitos biológicos que estão sendo estudados (OLIVEIRA, 2005; GARCIA et al., 2006). A soja apesar de apresentar relevante fator nutricional e ter importantes fatores biológicos benéficos à saúde humana, ainda é pouco utilizada na dieta do brasileiro. Seu sabor e odor desagradável característico, decorrentes da presença de diversos compostos orgânicos, podem ser uma das causas (SILVA et al., 2006; GARCIA et al., 2006; CHEYNIER, 2005).

A proteína e o óleo são os principais constituintes do grão de soja, representando cerca de $40 \%$ e $20 \%$, respectivamente (FELIX; CANNIATTI-BRAZACA, 2008; MONTEIRO et al., 2004). Ao comparar o grão de soja com o grão germinado, notase que na evolução do tempo de germinação da soja ocorrem aumento do conteúdo de umidade, proteínas, cinzas e fração glicídica (extrato não nitrogenado - ENN) (VILAS BOAS; BARCELOS; LIMA, 2002).

Entretanto, é relevante salientar que a soja contém componentes conhecidos como fatores antinutricionais, dentre eles, inibidores de proteases, lectinas, oligossacarídeos, fitatos e saponinas. A presença dos inibidores contribui para a redução da digestibilidade de suas proteínas. A quantidade desses inibidores indica quanto de proteína será hidrolisada pelas enzimas digestivas e absorvidas pelo organismo, também quanto será inibida a absorção do ferro e consequentemente diminuída sua biodisponibilidade (MONTEIRO et al., 2004; CARVALHO et al., 2002; FELIX; CANNIATTI-BRAZACA, 2008).

A redução da digestibilidade das proteínas da soja é multicausal, englobando a ação de fatores ligados à casca (principalmente taninos), aos cotilédones (fitatos e inibidores de protease) e ao processamento e armazenamento (FELIX; CANNIATTI-BRAZACA, 2008).

O teor total de ferro de um alimento não indica a quantidade que estará disponível, porque existem vários fatores que influenciam a absorção e utilização desse mineral. Dessa forma, para garantir suporte adequado de ferro, é necessário conhecer e diferenciar a quantidade total de ferro da quantidade biodisponível (FELIX; CANNIATTI-BRAZACA, 2008). Alguns compostos fenólicos podem reduzir a digestibilidade da proteína e a biodisponibilidade de minerais (DÍAZ-BATALLA et al., 2006).

O fitato, fator antinutricional presente nos grãos de soja, é também denominado mioinositol - 1, 2, 3, 4, 5, 6 hexa-dihidrogênio fosfato, componente abundante, com teor variando entre $1 \%$ e $1,5 \%$ da composição do grão (DEAK; JOHNSON, 2007; KUMAR et al., 2005). Representa a principal forma de armazenamento de fósforo (P) (de 50 a $70 \%$ do $\mathrm{P}$ total) e é acumulado durante a maturação e mobilizado para a germinação e crescimento da planta (LAZZARI, 2006).

$\mathrm{Na}$ leguminosa, o ácido fítico encontra-se na forma de ácido livre e forma um complexo com as proteínas e minerais presentes, especialmente os cátions de potássio, de magnésio, de cálcio, de ferro e de zinco, os quais não são prontamente absorvidos. Devido a sua ação quelante, o ácido fítico é considerado fator antinutricional, afetando a biodisponibilidade dos minerais e contribuindo para sua deficiência (DEAK; JOHNSON, 2007; LAZZARI, 2006; AL-WAHSH et al., 2005; SANDBERG, 2002). Estudos sugerem que o fitato tem ação anticarcinogênica em vários tipos de câncer. Em adição a esta atividade anticarcinogênica, o ácido fítico tem sido proposto para a redução da formação de cálculos renais, pois inibe a síntese de oxalatos de cálcio e cristais de fosfato de cálcio (AL-WAHSH et al., 2005; HORNER et al., 2005).

O ácido fítico é encontrado em alimentos altamente carregados negativamente e formam complexos ou ligações com moléculas de cargas positivas, tais como cátions metálicos e proteínas (DEAK; JOHNSON, 2007). Ocorrem diferentes mecanismos para a interação do fitato com a proteína, que depende dos diversos pHs ( $\mathrm{pH}<5, \mathrm{pH} 5-7$ e $\mathrm{pH}>7)$. Em pH baixo, a maioria das proteínas possui cargas positivas, enquanto que o ácido fítico apresenta-se carregado negativamente. Consequentemente, a interação proteína e ácido fítico é o resultado da forte interação eletrostática. Em pH intermediário, ambos possuem cargas negativas, e o complexo proteína-fitato permanece estável. Em pH elevado, cátions multivalentes, como o cálcio, são essenciais para a formação do complexo proteínafitato (DEAK; JOHNSON, 2007).

Nos grãos de soja, verificam-se também outros fatores antinutricionais (CARVALHO et al., 2002; MONTEIRO et al., 2004), dos quais, dois grupos são inibidores de protease: inibidor de tripsina Kunitz (KTI) e o inibidor de tripsina e quimiotripsina Bowman-Birk (BBI) (FELIX; CANNIATTI-BRAZACA, 2008). Por este motivo, a sua utilização é limitada, mesmo sem processamento prévio (MIURA et al., 2005; MONTEIRO et al., 2004). Representam cerca de $6 \%$ das proteínas presentes nos grãos de soja, estando localizados junto às principais proteínas de armazenamento no corpo proteico do cotilédone (MIURA et al., 2005). Cabe ressaltar que a atividade do inibidor de tripsina da soja apresenta efeito negativo tanto na digestão da proteína como na perda de nitrogênio endógeno no íleo terminal, o que acaba resultando em redução no coeficiente de digestibilidade aparente dos aminoácidos (FELIX; CANNIATTI-BRAZACA, 2008).

De maneira geral, para melhorar o valor nutricional da soja, há necessidade de tratamento térmico. Este tratamento deve ser controlado para evitar excesso de calor, que pode destruir aminoácidos importantes e diminuir a biodisponibilidade de outros nutrientes como compostos fitoquímicos (MONTEIRO et al., 2004).

Os taninos condensados estão presentes na fibra alimentar de diferentes alimentos e podem ser considerados indigeríveis ou pobremente digeríveis. Em leguminosas e cereais, os taninos têm recebido considerável atenção, por causa de seus efeitos adversos na cor, sabor e qualidade nutricional. A grande tendência dos taninos para formar complexos com proteínas ao invés de carboidratos e outros polímeros, pode explicar a baixa digestibilidade das proteínas de leguminosas, inibição 
do crescimento e aumento da excreção de nitrogênio fecal em animais (SILVA; SILVA, 1999).

Em relação à capacidade antioxidante da soja quando determinada pelo método $\mathrm{DPPH}$, esta pode variar de 1,3 a 5,1 $\mu$ moles equivalentes de Trolox/g de amostra, segundo Barbosa et al. (2006). Este método baseia-se na redução dos radicais livres pela abstração do $\mathrm{H}$ pelo antioxidante (BARBOSA et al., 2006).

A germinação é um processo biológico natural em que as sementes saem de seu estágio de latência, uma vez que as condições necessárias para o crescimento e desenvolvimento, tais como umidade, temperatura e nutrientes, dentre outros fatores são ofertados (SANGRONIS; MACHADO, 2007; VILAS BOAS; BARCELOS; LIMA, 2002). Durante a germinação, determinadas mudanças podem ocorrer, as quais podem variar dependendo do tipo do vegetal, da variedade da semente e das condições da germinação (SANGRONIS; MACHADO, 2007). Este fenômeno, além de proporcionar textura crocante e sabor diferenciado, eleva também seu valor nutritivo em virtude da melhoria da digestibilidade proteica e do valor do quociente de eficiência proteica (RIBEIRO, 2006). Em adição, a germinação promove redução dos fatores antinutricionais presentes, tais como inibidores proteolíticos e lectinas, provocando a hidrólise de oligossacarídeos (rafinose e estaquiose) da soja, os quais são causadores de flatulência. Cabe ressaltar, que a germinação também reduz o teor de fitatos, pelo aumento da atividade da enzima fitase. Ocorre aumento da biodisponibilidade de minerais e vitaminas (CREDE et al., 2004; VILAS BOAS; BARCELOS; LIMA, 2002; BAU; VILLAUME; MEJEAN, 2000; TRUGO et al., 2000).

Portanto, a germinação do grão parece ser um processo importante de melhora nutricional, cuja ação e disponibilidade de compostos fenólicos precisam ser mais bem investigadas (FELIX; CANNIATTI-BRAZACA, 2008; MONTEIRO et al., 2004).

O trabalho teve por objetivo quantificar e analisar as alterações ocorridas em grãos de soja antes e após a germinação. Para isso, foram analisados a composição centesimal dos grãos; os teores de inibidores de tripsina, de ácido fítico, de taninos, de fenólicos totais; a digestibilidade de ferro in vitro, a digestibilidade da proteína in vitro; e a capacidade antioxidante.

\section{Material e métodos}

\subsection{Matéria-prima}

Para a realização do experimento utilizaram-se grãos de soja (Glycine max (L.) Merrill) da variedade M. SOY RR, doados pelo Departamento de Produção Vegetal da Escola Superior de Agricultura “Luiz de Queiroz” - ESALQ/USP, Piracicaba, Estado de São Paulo, Brasil.

\subsection{Germinação}

Os grãos foram germinados em papel de germinação previamente umedecido com água potável. Posteriormente, os grãos foram cobertos com uma outra folha de papel de germinação, também umedecida, que foram dobradas e enroladas formando pacotes. A germinação ocorreu em câmara de germinação mantida a $25^{\circ} \mathrm{C}$ e $100 \%$ de umidade durante 48 horas. O tempo de 48 horas foi selecionado em testes preliminares, obtendo-se um broto de aparência atrativa para consumo.

\subsection{Composição centesimal}

Com a finalidade de caracterizar quimicamente as amostras foi realizada sua composição centesimal.

As análises de umidade, proteína bruta, lipídio, fibras alimentares (solúvel e insolúvel) e de cinzas foram realizadas de acordo com a metodologia indicada pela AOAC (ASSOCIATION..., 2005). O conteúdo de carboidrato foi calculado por diferença.

\subsection{Fatores antinutricionais}

A determinação de fatores antinutricionais foi realizada nas amostras de grãos antes e após germinação.

\section{Inibidores de tripsina}

A atividade inibitória de tripsina foi determinada de acordo com Kakade, Simons e Liener (1969), usando-se benzoil-DLarginina- $\rho$-nitroanilida (BAPA) como substrato. Os resultados foram expressos como UTI por g de proteína.

\section{Ácido fítico}

O teor total de ácido fítico nas amostras foi determinado segundo o método descrito por Grynspan e Cheryan (1989), sendo obtido o teor de ácido fítico a partir da construção de curva padrão e os resultados foram expressos em mg de ácido fítico.g $\mathrm{g}^{-1}$ de amostra.

\section{Taninos condensados}

Os taninos foram analisados segundo a metodologia descrita por Hagerman e Butler (1978), utilizando-se da curva de catequina como padrão.

\section{Fenólicos totais}

A determinação da concentração de fenólicos totais foi realizada segundo metodologia descrita por Deshpande e Cheryan (1987), através de extração com metanol, adição de reagente Folin-Denis, saturação com carbonato de sódio e posterior leitura de absorbância a $660 \mathrm{~nm}$.

\subsection{Ferro}

\section{Teor de ferro}

Para a análise do teor de ferro, foi utilizado ácido nítrico para a digestão nitroperclórica das amostras a $50{ }^{\circ} \mathrm{C}$ por 10 a 15 minutos, a $100{ }^{\circ} \mathrm{C}$, até digerir todo o material e atingir a temperatura de $150{ }^{\circ} \mathrm{C}$. Após resfriamento e diluição do material com água desmineralizada, foi realizada a leitura em espectrofotômetro de absorção atômica. 


\section{Disponibilidade de ferro}

A análise da diálise de ferro foi realizada segundo o método proposto por Whittaker et al. (1989).

\subsection{Digestibilidade in vitro da proteína}

A digestibilidade in vitro foi determinada segundo metodologia descrita por Akeson e Stahman (1964), a qual se baseia na hidrólise enzimática das proteínas com pepsina e pancreatina, seguida da determinação do nitrogênio não precipitável com ácido pícrico. Do sobrenadante, foi determinado o nitrogênio através do método Microkjeldahl (ASSOCIATION..., 2005).

\subsection{DPPH}

A capacidade antioxidante dos extratos das sojas foi medida segundo método proposto por Brand-William, Cuvier e Berset (1995), utilizando 1,1-difenil-2-picril-hidrazil (DPPH). O padrão utilizado de comparação foi o Trolox. A absorbância foi medida a 517 nm (SINGH; MURTH; JAYAPRAKASHA, 2002).

\subsection{ABTS}

O padrão TEAC descrito por Berg et al. (1999) e Re et al. (1999), que usa a determinação dos valores de TEAC com algumas modificações, foi utilizado. A TEAC foi calculada em relação à solução de Trolox (ARTS et al., 2004).

\subsection{Análise estatística}

O delineamento estatístico foi inteiramente casualizado com três repetições por tratamento. Os resultados foram submetidos à análise estatística pelo teste de Tukey a 5\% de probabilidade utilizando o software SAS (STATISTICAL..., 1998).

\section{Resultados e discussão}

Os dados referentes à composição centesimal dos grãos de soja controle e germinados são apresentados na Tabela 1.

Como pode ser observado, os teores de lipídio, proteína e fibra solúvel diferiram estatisticamente entre as duas amostras analisadas $(p \leq 0,05)$, enquanto que os teores de cinzas e fibra insolúvel não apresentaram diferenças significativas.

Tabela 1. Composição centesimal (base seca, média \pm desvio padrão) da soja antes e após germinação por 48 horas.

\begin{tabular}{lcc}
\hline \multicolumn{1}{c}{ Constituinte (\%) } & $\begin{array}{c}\text { Soja antes } \\
\text { da germinação }\end{array}$ & $\begin{array}{c}\text { Soja após } \\
\text { germinação }\end{array}$ \\
\hline Umidade & $6,71 \pm 0,2^{\mathrm{b}}$ & $63,72 \pm 0,2^{\mathrm{a}}$ \\
Lipídio & $22,05 \pm 0,1^{\mathrm{b}}$ & $23,11 \pm 0,3^{\mathrm{a}}$ \\
Proteína & $35,67 \pm 0,5^{\mathrm{b}}$ & $42,02 \pm 1,1^{\mathrm{a}}$ \\
Cinza & $5,11 \pm 0,1^{\mathrm{a}}$ & $5,09 \pm 0,1^{\mathrm{a}}$ \\
Fibra solúvel & $0,18 \pm 0,0^{\mathrm{a}}$ & $2,15 \pm 0,3^{\mathrm{b}}$ \\
Fibra insolúvel & $15,88 \pm 0,5^{\mathrm{a}}$ & $17,82 \pm 1,5^{\mathrm{a}}$ \\
Carboidrato disponível & 21,11 & 9,81 \\
\hline Letras diferentes na linha indicam diferença estatística significativa $(p \leq 0,05), \mathrm{n}=3$.
\end{tabular}

O percentual de umidade entre as amostras apresentou média de $6,71 \%$ para soja controle e $63,73 \%$ para soja germinada. Esse resultado pode ser explicado, pois durante o processo de germinação ocorre hidratação das sementes a fim de promover o crescimento da planta (VILLELA; NOVEMBRE; MARCOS FILHO, 2007).

Quanto aos valores obtidos para o lipídio, foi observado maior conteúdo na soja germinada $(23,11 \%)$ quando comparado ao grão controle $(22,05 \%)$. Porém resultados diferentes e contraditórios foram observados na literatura. O conteúdo de lipídio nas sementes diminui com a evolução no tempo de germinação (VILAS BOAS; BARCELOS; LIMA, 2002; BAU et al., 1997; RIBEIRO; IDA; OLIVEIRA, 1997). Essa diminuição é atribuída à degradação de reservas de nutrientes (lipídio e carboidrato) para o fornecimento de energia requerida durante o crescimento da planta (MUBARAK, 2005; EL-ADAWY, 2002; BAU et al., 1997; RIBEIRO; IDA; OLIVEIRA, 1997). No entanto, embora ocorra oxidação durante o processo, a análise de lipídio não detecta esta alteração. Uma justificativa para tal fato é o tempo de germinação de 48 horas, já que na literatura essa redução ocorre somente a partir de 72 horas.

O teor de proteína foi de 35,67\% (controle) e 42,02\% (germinada). Esse maior conteúdo de proteína na soja germinada era esperado, visto que durante este processo ocorre a síntese enzimática proteica (BAU et al., 1997) ou a mudança na composição que segue a degradação de outros constituintes (MUBARAK, 2005; EL-ADAWY, 2002; BARCELOS; VILLAS BOAS; LIMA, 2002; BAU et al., 1997; RIBEIRO; IDA; OLIVEIRA, 1997).

Os resultados das cinzas são condizentes com os apresentados por Vilas Boas, Barcelos e Lima (2002), nos quais não foi observada diferença estatística $(p \geq 0,05)$ entre o grão controle e o germinado em um período de 3 dias. Os teores obtidos por esses autores $(4,02 \%$ no controle e $4,08 \%$ no germinado) foram similares ao presente estudo (Tabela 1). Segundo Vilas Boas, Barcelos e Lima (2002) o aumento no teor de cinzas foi observado somente no quarto dia de germinação.

Os teores de fibras apresentaram aumento após germinação, e não foi observada diferença estatística significativa entre as amostras analisadas para fibras insolúveis. Ghavidel e Prakash (2007) demonstraram que, após germinação, as fibras totais e as frações dietéticas solúveis aumentaram e a fração insolúvel reduziu significativamente, considerando, entretanto, um período de germinação maior que o do presente estudo.

As quantidades analisadas de carboidratos disponíveis, obtidos por diferença, nas amostras analisadas, apresentaram valores de $21,11 \%$ para a soja controle e $9,81 \%$ para a soja germinada. A partir destes dados, observa-se redução significativa nos teores deste macronutriente para a soja germinada. Isso pode ser decorrente do seu uso como fonte de energia para o início da germinação (MUBARAK, 2005; EL-ADAWY, 2002). Como os carboidratos totais, solúveis da soja, são constituídos de sacarose, rafinose e estaquiose (oligossacarídeos), estes possivelmente foram hidrolisados 
durante este processo (MUBARAK, 2005; EL-ADAWY, 2002). Sendo a rafinose e a estaquiose consideradas como fatores de flatulência, sua degradação ou redução são desejáveis (RIBEIRO; IDA; OLIVEIRA, 1997).

Os resultados obtidos na atividade inibitória de tripsina, ácido fítico, taninos condensados e fenólicos totais estão apresentados na Tabela 2 .

Conforme dados apresentados na Tabela 2, observa-se que os inibidores de tripsina na soja germinada tiveram as suas atividades diminuídas quando comparados aos da soja controle, porém não diferiram estatisticamente $(\mathrm{p}>0,05)$.

A análise de variância dos resultados obtidos na determinação do teor de ácido fítico, apesar de apresentar pequena redução, não diferiu estatisticamente entre as amostras controle e germinada. Estudo realizado por Ayet et al. (1997) verificou que os teores de ácido fítico não diminuíram durante os primeiros 3 dias de germinação; após este período foi detectada redução acentuada em seus níveis. Bau et al. (1997) afirmaram que após 5 dias de germinação da soja, seus teores de ácido fítico diminuíram em torno de $17 \%$ e, após 12 dias de germinação, esta redução pode chegar a aproximadamente $50 \%$. Devido ao curto período de germinação de 48 horas não ocorreu diminuição significativa do ácido fítico (Tabela 2).

Segundo Bau et al. (1997), no início da germinação, há redução gradativa na atividade inibitória de tripsina, a qual contribui para a elevação da digestibilidade de suas proteínas. Diversos estudos relatam que, durante a germinação, o aumento da atividade da enzima fitase ocorre, contribuindo para a redução do ácido fítico (SANGRONIS; MACHADO, 2007; GHAVIDEL; PRAKASH, 2007; MUBARAK, 2005; CREDE et al., 2004; OLOYO, 2004; BARCELOS; VILAS BOAS; LIMA, 2002; RIBEIRO; IDA; OLIVEIRA, 1999; AYET et al., 1997; BAU et al., 1997), com possível aumento na disponibilidade de minerais, vitaminas e proteínas (NWABUEZE, 2007; CREDE et al., 2004).

As análises de variâncias de taninos condensados e fenólicos totais indicaram diferença estatística entre as amostras analisadas (Tabela 2).

Oloyo (2004) afirma que a concentração de taninos em leguminosas diminui após 2 dias de germinação alcançando o seu nível mínimo, e que após o quinto dia seus teores elevam. Foi observada (Tabela 2) redução de aproximadamente $23 \%$

Tabela 2. Atividade inibitória de tripsina (UTI.mg-1), teor de ácido fítico ( $\left.\mathrm{mg} \cdot \mathrm{g}^{-1}\right)$, teor de taninos condensados $\left(\mathrm{mg} \mathrm{g}^{-1}\right)$ e teor de fenólicos totais $\left(\mathrm{mg}^{-\mathrm{g}^{-1}}\right.$ ) em soja antes e após germinação por 48 horas (média \pm desvio padrão).

\begin{tabular}{lcc}
\hline \multicolumn{1}{c}{ Análises } & $\begin{array}{c}\text { Soja antes } \\
\text { da germinação }\end{array}$ & $\begin{array}{c}\text { Soja após } \\
\text { germinação }\end{array}$ \\
\hline Atividade inibitória de tripsina & $181,93 \pm 15,5^{\mathrm{a}}$ & $169,98 \pm 14,3^{\mathrm{a}}$ \\
Ácido fítico & $13,68 \pm 0,8^{\mathrm{a}}$ & $12,77 \pm 0,6^{\mathrm{a}}$ \\
Taninos condensados & $4,48 \pm 0,3^{\mathrm{a}}$ & $3,45 \pm 0,2^{\mathrm{b}}$ \\
Fenólicos totais & $16,89 \pm 0,9^{\mathrm{b}}$ & $27,93 \pm 2,9^{\mathrm{a}}$ \\
\hline
\end{tabular}

Letras diferentes na linha indicam diferença estatística significativa $(p \leq 0,05), \mathrm{n}=3$. após 48 horas de germinação. Essa redução tem sido discutida entre os autores que afirmam que a oxidação de polifenóis está ativada durante a germinação, causando hidrólise enzimática de taninos com consequente redução (SANGRONIS; MACHADO, 2007; GHAVIDEL PRAKASH, 2007; TORRES et al., 2006).

Em relação ao teor de fenólicos totais, foi observado aumento em seu conteúdo após germinação. Resultados estes discrepantes dos de Lin e Lai (2006) que encontraram diminuição significativa após o período de germinação. Porém essa concentração pode variar muito, pois depende de inúmeros fatores, dentre eles: método de determinação, compostos determinados, procedimentos para a germinação, entre outros fatores (BARBOSA et al., 2006).

Os resultados obtidos do teor de ferro e sua disponibilidade estão apresentados na Tabela 3.

De acordo com a Tabela 3, o teor de ferro não apresentou diferença estatística $(p>0,05)$. A análise do ferro indica a quantidade do mineral presente nas amostras, porém não indica quanto deste ferro será realmente absorvido. Sabe-se que nem todo o ferro presente no alimento é absorvido, podendo ser total ou parcialmente utilizado pelo indivíduo (FELIX; CANNIATTIBRAZACA, 2008).

Estudo realizado por Brigide e Canniatti-Brazaca (2006), o qual avaliou o benefício da irradiação no feijão, afirma que os processos como maceração, cocção, assim como germinação são responsáveis pela inativação dos fatores antinutricionais, e consequentemente melhoram na disponibilidade de ferro, além de assegurar textura, sabor e aroma para consumo. Uma explicação por não haver melhora da disponibilidade do ferro seria devido ao pequeno tempo de germinação utilizado (48 horas).

O ácido fítico tem sido destacado por ser um dos fatores responsáveis pela redução da biodisponibilidade de minerais, porém em relação à germinação esse fator tem efeito reduzido proporcionando aumento na qualidade nutricional (BRIGIDE; CANNIATTI-BRAZACA, 2006). Esses dados demonstram que os valores encontrados para o ácido fítico (Tabela 2) em relação à concentração de ferro dialisável não apresentaram diferenças significativas (Tabela 3 ). Esse comportamento pode ser justificado devido à pequena redução, embora não significativa, nos teores de ácido fítico após 2 dias de germinação.

Os valores obtidos na análise da digestibilidade da proteína in vitro estão apresentados na Tabela 4.

Os valores da digestibilidade da proteína in vitro foram de $31,74 \%$ para soja controle e $39,81 \%$ para soja germinada, e diferiram estatisticamente entre si.

Tabela 3. Teor de ferro ( $\left.\mu \mathrm{g} \cdot \mathrm{g}^{-1}\right)$ e disponibilidade de ferro (\%) em soja antes e após germinação por 48 horas (média \pm desvio padrão).

\begin{tabular}{lcc}
\hline \multicolumn{1}{c}{ Amostras } & Teor de ferro & Disponibilidade de ferro \\
\hline Soja antes da germinação & $1,15 \pm 0,1^{\mathrm{a}}$ & $1,64 \pm 0,0^{\mathrm{a}}$ \\
Soja após germinação & $1,10 \pm 0,1^{\mathrm{a}}$ & $1,54 \pm 0,0^{\mathrm{a}}$ \\
\hline Letras diferentes na coluna indicam diferença estatística significativa $(p \leq 0,05), \mathrm{n}=3$.
\end{tabular}


A germinação aumentou significativamente a digestibilidade da proteína comparada à amostra controle. Esse aumento foi de aproximadamente $25 \%$, e está atribuído à desnaturação da proteína, à destruição do inibidor de tripsina e à redução nos teores de taninos e ácido fítico (TORRES et al., 2006; MUBARAK, 2005; EL-ADAWY, 2002). O ácido fítico e os taninos condensados interagem com as moléculas de proteína, formando complexos com consequente redução da susceptibilidade da proteína aos ataques enzimáticos (SANGRONIS; MACHADO, 2007).

Foi observada redução significativa nos teores de taninos e redução não significativa nos teores de ácido fítico e inibidor de tripsina (Tabela 2). A partir desses dados, conclui-se que o aumento da digestibilidade de proteína in vitro pode ser justificado devido às alterações obtidas de taninos condensados, ácido fítico e inibidor de tripsina.

A soja antes da germinação, que apresentou a maior atividade para os inibidores (Tabela 2), obteve o menor valor para digestibilidade in vitro $(32,5 \%)$ (Tabela 4 ). O mesmo foi verificado no estudo de Carvalho et al. (2002), os quais observaram que os valores de atividade dos inibidores correlacionaram-se negativamente com a porcentagem de digestibilidade.

Os valores obtidos da atividade antioxidante nas análises realizadas pelo método DPPH e ABTS utilizando como padrão Trolox estão apresentados na Tabela 5.

Foi observada diferença significativa entre a amostra germinada e controle $(p<0,05)$ em ambos os métodos. Estes se baseiam na redução do radical pela abstração do hidrogênio pelo antioxidante. Desta forma, pode-se constatar que a soja controle apresenta capacidade redutora maior em relação à amostra germinada, para ambos os métodos, provavelmente devido à diminuição de substâncias antioxidantes que ocorrem durante a germinação, como os compostos fenólicos, taninos e ácido fítico (Tabela 2).

Quando observada a correlação entre a determinação de fenólicos totais e a atividade antioxidante para os métodos ABTS e DPPH, constata-se que a soja germinada possui menor teor de fenólico total (Tabela 2) e menor capacidade antioxidante

Tabela 4. Digestibilidade da proteína in vitro (\%) em soja antes e após germinação por 48 horas (média \pm desvio padrão).

\begin{tabular}{lc}
\hline \multicolumn{1}{c}{ Amostras } & Digestibilidade da proteína $(\%)$ \\
\hline Soja antes da germinação & $32,53 \pm 1,4^{\mathrm{b}}$ \\
Soja após germinação & $40,32 \pm 1,3^{\mathrm{a}}$ \\
\hline Letras diferentes na coluna indicam diferença estatística significativa $(p \leq 0,05), \mathrm{n}=3$.
\end{tabular}

Tabela 5. Atividade antioxidante ( $\mu \mathrm{Mol}$ Trolox) determinada pelos métodos DPPH e ABTS de extratos metanólicos de soja antes e após germinação por 48 horas (média \pm desvio padrão).

\begin{tabular}{lcc}
\hline \multicolumn{1}{c}{ Amostras } & DPPH $(\mu \mathrm{Mol})$ & ABTS $(\mu \mathrm{Mol})$ \\
\hline Soja antes da germinação & $0,20 \pm 0,0^{\mathrm{a}}$ & $5,98 \pm 0,0^{\mathrm{a}}$ \\
Soja após a germinação & $0,04 \pm 0,0^{\mathrm{b}}$ & $5,86 \pm 0,0^{\mathrm{b}}$ \\
\hline Letras diferentes na coluna indicam diferença estatística significativa $(p \leq 0,05), \mathrm{n}=3$.
\end{tabular}

(Tabela 5), ou seja, foi detectado que em 1,97 mg de fenólicos totais em soja controle apresenta atividade antioxidante pelo método ABTS de 5,97 $\mu$ mol Trolox. Já a soja germinada possui $3,30 \mathrm{mg}$ de fenólicos totais com atividade antioxidante de $5,86 \mu \mathrm{mol}$ Trolox.

\section{Conclusões}

A germinação apresenta efeito na composição química e disponibilidade de proteínas e ferro.

A germinação resultou na redução significativa nos teores de taninos condensados, carboidratos disponíveis e atividade antioxidante pelos métodos DPPH e ABTS. Em contrapartida, o processo promoveu aumento no teor de umidade, lipídio, proteína, fibra solúvel, digestibilidade in vitro de proteína e fenólicos totais. Não apresentou diferença estatística para os teores de cinzas, fibra insolúvel, teor de ferro, disponibilidade de ferro, ácido fítico e atividade inibitória de tripsina.

Portanto, para o processo de germinação de 48 horas, o consumo de grãos de soja germinado pode trazer maior benefício para o aproveitamento das proteínas presentes no grão do que o grão antes da germinação.

\section{Agradecimentos}

Ao Departamento de Produção Vegetal da Escola Superior de Agricultura "Luiz de Queiroz" - ESALQ/USP, Piracicaba, Estado de São Paulo, Brasil pela doação dos grãos e pela utilização da estufa de germinação.

\section{Referências bibliográficas}

AKESON, W. R.; STAHMAN, M. A. A pepsina pancreatin digest index of protein quality evaluation. Journal Nutrition, v. 83, n. 3 , p. 257-261, 1964.

AL-WAHSH, I. A. et al. Oxalate and Phytate of soy foods. Journal of Agricultural and Food Chemistry, v. 53, p. 5670-5674, 2005.

ARTS, M. J. T. J. et al. A new approach to assess the total antioxidant capacity using the TEAC assay. Food Chemistry, v. 88, n. 4, p. 567-570, 2004.

ASSOCIATION OF OFFICIAL ANALYTICAL CHEMISTS - AOAC. Official Method of Analysis. $18^{\text {th }}$ ed. Washington, DC, USA: AOAC, 2005.

AYET, G. et al. Effect of germination, under different environmental conditions, on saponins, phytic acid and tannins in lentils (Lens Culinaris). Journal Science Food Agriculture, v. 74, p. 273-279, 1997.

BARBOSA, A. C. L. et al. Teores de isoflavonas e capacidade antioxidante da soja e produtos derivados. Ciência e Tecnologia de Alimentos, v. 26, n. 4, p. 921-926, 2006.

BARCELOS, M. F. P.; VILAS BOAS, E. V. B.; LIMA, M. A. C. Aspectos nutricionais de brotos de soja e de milho combinados. Ciência e Agrotecnologia, v. 26, n. 4, p. 817-825, 2002.

BAU, H. M. et al. Effect of germination on chemical composition, biochemical constituents and antinutritional factors of soya bean (Glycine max) seeds. Journal Science Food Agriculture, v. 73, p. 1-9, 1997.

BAU, H. M.; VILLAUME, C. H.; MÉJEAN, L. Effects of soybean (Glycine max) germination on biologically active components, 
nutritional values of seeds, and biological characteristics in rats. Nahrung, v. 44, n. 1, p. S2-S6, 2000.

BERG, V. D. et al. Applicability of an improved Trolox equivalent antioxidant capacity (TEAC) assay for evaluation of antioxidant capacity measurements of mixtures. Food Chemistry, v. 66, p. 511-517, 1999.

BRAND-WILLIAMS, W.; CUVIER, M. E.; BERSET, C. Use of a free radical method to evaluate antioxidant activity. LebensmittelWissenschaft \& Technologie, v. 28, p. 25-30, 1995.

BRIGIDE, P.; CANNIATTI-BRAZACA, S. G. Antinutrients and in vitro availability iron of irradiated common beans (Phaseolus vulgaris $\mathrm{L}$.) Food Chemistry, v. 98, n. 1, p. 85-89, 2006.

CARVALHO, M. R. B. et al. Avaliação da atividade dos inibidores de tripsina após digestão enzimática em grãos de soja tratados termicamente. Revista de Nutrição, v. 15, n. 3, p. 267-272, 2002.

CHEYNIER, V. Polyphenols in foods are more complex than often thought. American Journal of Clinical Nutrition, v. 81, supl., p. 223S-229S, 2005.

CREDE, R. G. et al. Germinometria de grãos de milho (Zea mays) e soja (Glycine max) tratados por radiação ionizante. Arquivos do Instituto de Biológico, v. 71 (Supl.), p. 1-49, 2004.

DEAK, N. A.; JOHNSON, L. A. Fate of Phytic Acid in producing soy protein ingredients. Journal of American Oil Chemistry Society, v. 84, p. 369-376, 2007.

DESHPANDE, S. S.; CHERYAN, M. Determination of phenolic compounds of dry beans using vanilin, redox and precipitation assays. Journal of Food Science, v. 52, n. 2, p. 332-334, 1987.

DÍAZ-BATALLA, L. et al. Chemical components with health implications in wild and cultivated Mexican common bean seeds (Phaseolus vulgaris L.). Journal Agricultural and Food Chemistry, v. 54, p. 2045-2052, 2006.

EL-ADAWY, T. Nutritional composition and antinutritional factors of chickpeas (Cicer arietinum L.) undergoing different cooking methods and germination. Plant Foods for Human Nutrition, v. 57, p. 83-97, 2002.

EMBRAPA. A soja. 2004. Disponível em: <http://www.cnpso.embrapa. br > . Acesso em: 04 jun. 2007.

FELIX, M. A.; CANNIATTI-BRAZACA, S. G. Disponibilidade de ferro in vitro de grãos de soja tostados por diferentes tratamentos. Ciência e Tecnologia de Alimentos, v. 28, 2008.

GARCIA, J.R. et al. Valoración de la capacidad antioxidante y actividad polifenol oxidasa en duraznos de diferentes áreas de producción. In: SIMPOSIO IBERO-AMERICANO DE VEGETAIS FRESCOS XORTADOS, 1., 2006, San Pedro, SP. Anais...

GHAVIDEL, R. A.; PRAKASH, J. The impact of germination and dehulling on nutrients, antinutrients, in vitri iron and calcium bioavailability and in vitro starch and protein digestibility of some legume seeds. LWT Food Science and Technology, v. 40, p. 1292-1299, 2007.

GRYNSPAN, F.; CHERYAN, M. Phytate-calcium interaction with soy protein. Journal of the American Oil Chemists Society, v. 66, n. 1, p. 93-97, 1989.

HAGERMAN, A.E.; BUTLER, L.G. Protein precipitation method for the quantitative determination of tannins. Journal of Agricultural and Food Chemistry, v. 26, n. 4, p. 809-812, 1978.

HORNER, H. T. et al. Oxalate and phytate concentrations in seeds of soybean cultivars (Glycine max (L.) Merr). Journal of Agricultural and Food Chemistry, v. 53, p. 7870-7877, 2005.
INSTITUTO BRASILEIRO DE GEOGRAFIA E ESTATISTICA - IBGE. Grupo de Coordenação de Estatísticas Agropecuárias - GCEA/ IBGE, DPE, COAGRO. Prognóstico da produção agrícola nacional. Levantamento sistemático da produção agrícola-Outubro 2006. Disponível em: <http://www.ibge.gov.br/home/estatistica/ indicadores/agropecuaria/Ispa/Ispa10200610 > . Acesso em: 13 jun. 2007.

KAKADE, M. L.; SIMONS, N.; LIENER, I. E. An evaluation of natural vs. synthetic substrates for measuring the anti tryptic activity of soybean samples. Cereal Chemitry, v. 46, p. 518-526, 1969.

KUMAR, V. et al. Phytic acid in Indian soybean: genotypic variability and influence of growing location. Journal of Science and Food Agricultural, v. 85, p. 1523-1526, 2005.

LAZZARI, E. N. Análise de ácido fítico e minerais nos processos de maceração e cocção de soja. Londrina, 2006.

LIN, P. Y.; LAI, H. M. Bioactive compounds in legumes and their germinated products. Journal of Agricultural of Food Chemistry, v. 54, p. 3807-3814, 2006.

MELO, E. A.; MARCOS FILHO, J.; GUERRA, N. B. Characterization of antioxidant compounds in aqueous coriander extract (Coriandrum sativum L.). LWT Food Science and Technology, v. 38, p. 15-19, 2005.

MIURA, E. M. Y. et al. Cinética de inativação de Inibidores de Tripsina e de Insolubilização de Proteínas de diferentes cultivares de soja. Revista Brasileira de Zootecnia, v. 34, n. 5, p. 1659-1665, 2005.

MONTEIRO, M. R. P. et al. Qualidade protéica de linhagens de soja com ausência do Inibidor de Tripsina Kunitz e das isoenzimas Lipoxigenases. Revista de Nutrição, v. 17, n. 2, p. 195-205, 2004.

MUBARAK, A. E. Nutritional composition and antinutritional factors of mung bean seeds (Phaseolus aureus) as affected by some home traditional process. Food Chemistry, v. 89, p. 489-495, 2005.

NWABUEZE, T. U. Effect of process variables on trypsin inhibitor activity (TIA), phytic acid and tannin content of extruded African breadfruit-corn-soy mixtures: A response surface analysis. LWT Food Science and Technology, v. 40, p. 21-29, 2007.

OLIVEIRA, M. A. Extração de polifenóis da semente de cacau. Florianópolis, SC, 2005.

OLOYO, R. A. Chemical and nutrition quality changes in germinating seeds of Cajanus cajan L. Food Chemistry, v. 85, p. 497-502, 2004.

RE, R. et al. Antioxidant activity applying na improved ABST radical cation decolorization assay. Free Radical Biology, v. 26, n. 9/10, p. 1231-1237, 1999.

RIBEIRO, M. L. L. Teor de isoflavonas e atividade de $\beta$-glucosidase em grãos de soja germinada e de diferentes grupos de maturação. Purificação e caracterização bioquímica parcial da $\beta$-glucosidase. Londrina, 2006.

RIBEIRO, M. L. L.; IDA, E. I.; OLIVEIRA, M. C. N. Efeito da germinação de soja CV. BR - 13 e Paraná sobre ácido fítico, fósforo total e inibidores de tripsina. Pesquisa Agropecuária Brasileira, v. 34, n. 1, p. 31-36, 1999.

RIBEIRO, M.L.L; IDA, E.I.; OLIVEIRA, M.C.N. Germinação de soja BR - 13 e Paraná: efeito sobre os constituintes minerais. Archivos Latinoamericanos de Nutrition, v.47, n.4, p.352-358, 1997.

SANDBERG, A. Bioavailability of minerals in legumes. British Journal of Nutrition, v. 88, Suppl. 3, p. S281-S285, 2002.

SANGRONIS, E.; MACHADO, C. J. Influence of germination on the nutritional quality of Phaseolus vulgaris and Cajanus cajan. LWT Food Science and Tecnology, v. 40, p. 116-120, 2007. 
SILVA, M. R.; SILVA, M. A. A. P. Aspectos nutricionais de fitatos e taninos. Revista de Nutrição, v. 12, n. 1, p. 5-19, 1999.

SILVA, M. S. et al. Composição química e valor protéico do resíduo de soja em relação ao grão de soja. Ciência e Tecnologia de Alimentos, v. 26, n. 3, p. 571-576, 2006.

SINGH, K. N.; MURTHY, G. K.; JAYAPRAKASHA, C. Studies on the antioxidant activity of pomegranate (Punica garanatum) peel and seed extracts using in vitro models. Journal of Agricultural and Food Chemistry, v. 50, p. 81-86, 2002.

STATISTICAL ANALYSIS SYSTEM INSTITUTE. Sas/Qc Software: usage and referente. $2^{\text {nd }}$ ed. Cary, 1998. 2 v.

TORRES, A. et al. Protein quality of germinated Phaseolus vulgaris. European Food Research Technolology, v. 222, p. 144-148, 2006.
TRUGO, L. C. et al. Effect of heat treatment on nutritional quality of germinated legume seeds. Journal of Agricultural and Food Chemistry, v. 48, p. 2082-2086, 2000.

VILAS BOAS, E. V. B.; BARCELOS, M. F. P.; LIMA, M. A. C. Tempo de germinação e característica físicas, químicas e sensoriais dos brotos de soja e de milho combinado nas formas isoladas e combinadas. Ciência e Agrotecnologia, v. 26, n. 1, p. 148-156, 2002.

VILLELA, F. A.; NOVEMBRE, A. D. L. C.; MARCOS FILHO, J. Estado energético da água na germinação de sementes de soja. Revista Brasileira de Sementes, v. 29, n. 1, p. 27-34, 2007.

WHITTAKER, P.; SPIVEY FOX, M. R.; FORBES, A. L. In vitro prediction of iron bioavailability for food fortification. Nutrition Report International, v. 39, n. 6, p. 1205-1215, 1989. 